\title{
A Microbiome-Derived Peptide Induces Apoptosis of Cells from Different Tissues
}

\author{
Haruko Saiki ${ }^{1,+}$, Yuko Okano ${ }^{2,3,+}$, Taro Yasuma ${ }^{2,3, \dagger}$, Masaaki Toda ${ }^{2,+}$, Atsuro Takeshita ${ }^{2,3}$, \\ Ahmed M. Abdel-Hamid 4,5, Valeria Fridman D’Alessandro 20, Tatsuki Tsuruga ${ }^{1}$, \\ Corina N. D'Alessandro-Gabazza ${ }^{2}$, Kan Katayama ${ }^{6}$, Masahiko Sugimoto ${ }^{7}{ }^{(1)}$, Hajime Fujimoto ${ }^{1}$, \\ Keiichi Yamanaka ${ }^{8}$ (D), Tetsu Kobayashi ${ }^{1}$, Isaac Cann ${ }^{5,9}$ and Esteban C. Gabazza ${ }^{2,5, *(\mathbb{D})}$
}

1 Department of Pulmonary and Critical Care Medicine, Faculty and Graduate School of Medicine, Mie University, Tsu 514-8507, Mie, Japan; harusakusa@yahoo.co.jp (H.S.); y.o.spriggan@gmail.com (T.T.); genfujimoto1974@yahoo.co.jp (H.F.); kobayashitetsu@hotmail.com (T.K.)

2 Department of Immunology, Faculty and Graduate School of Medicine, Mie University, Tsu 514-8507, Mie, Japan; yu.higako@gmail.com (Y.O.); t-yasuma0630@clin.medic.mie-u.ac.jp (T.Y.); t-masa@doc.medic.mie-u.ac.jp (M.T.); johnpaul0114@yahoo.co.jp (A.T.); immunol@doc.medic.mie-u.ac.jp (V.F.D.); dalessac@clin.medic.mie-u.ac.jp (C.N.D.-G.)

3 Department of Diabetes, Endocrinology and Metabolism, Faculty and Graduate School of Medicine, Mie University, Tsu 514-8507, Mie, Japan

4 Department of Botany and Microbiology, Faculty of Science, Minia University, El-Minia 61519, Egypt; ahetta@illinois.edu

Citation: Saiki, H.; Okano, Y.; Yasuma, T.; Toda, M.; Takeshita, A.; Abdel-Hamid, A.M.; Fridman D'Alessandro, V.; Tsuruga, T.; D'Alessandro-Gabazza, C.N.;

Katayama, K.; et al. A

Microbiome-Derived Peptide Induces Apoptosis of Cells from Different Tissues. Cells 2021, 10, 2885. https:// doi.org/10.3390/cells10112885

Academic Editor: Maria

Cristina Curia

Received: 6 September 2021

Accepted: 7 October 2021

Published: 26 October 2021

Publisher's Note: MDPI stays neutral with regard to jurisdictional claims in published maps and institutional affiliations.

Copyright: () 2021 by the authors. Licensee MDPI, Basel, Switzerland. This article is an open access article distributed under the terms and conditions of the Creative Commons Attribution (CC BY) license (https:// creativecommons.org/licenses/by/ $4.0 /)$.
5 Carl R. Woese Institute for Genomic Biology (Microbiome Metabolic Engineering), University of Illinois at Urbana-Champaign, Urbana, IL 61801-3633, USA; icann@illinois.edu

6 Department of Cardiology and Nephrology, Faculty and Graduate School of Medicine, Mie University, Tsu 514-8507, Mie, Japan; katayamk@clin.medic.mie-u.ac.jp

7 Department of Ophthalmology, Faculty and Graduate School of Medicine, Mie University, Tsu 514-8507, Mie, Japan; sugmochi@clin.medic.mie-u.ac.jp

8 Department of Dermatology, Faculty and Graduate School of Medicine, Mie University, Tsu 514-8507, Mie, Japan; yamake@clin.medic.mie-u.ac.jp

9 Departments of Animal Science, and Microbiology, The University of Illinois at Urbana-Champaign, Urbana, IL 61801-3633, USA

* Correspondence: gabazza@doc.medic.mie-u.ac.jp; Tel.: +81-59-231-5037

+ These authors contributed equally to this work.

Abstract: Apoptosis is a programmed cell death involved in embryogenesis and tissue homeostasis under physiological conditions. However, abnormalities in the process of apoptosis are implicated in the pathogenesis of various diseases. The human microbiota may release products that induce apoptosis of host cells. We recently identified a novel microbiome-derived peptide called corisin that worsens lung fibrosis by inducing apoptosis of lung epithelial cells. We hypothesized that corisin and a corisin-like peptide might also induce apoptosis of cells from different tissues. We cultured podocytes, renal tubular epithelial cells, keratinocytes, retinal and intestinal cells treated with corisin and evaluated apoptosis by flow cytometry and Western blotting. Although at different grades, flow cytometry analysis and Western blotting showed that corisin and a corisin-like peptide induced apoptosis of podocytes, keratinocytes, tubular epithelial cells, retinal, and intestinal cells. In addition, we found that corisin synergistically enhances the proapoptotic activity of transforming growth factor- $\beta 1$ on podocytes. In conclusion, these results suggest that corisin and corisin-like peptides may play a role in the pathogenesis of disease in different organs by promoting apoptosis of parenchymal cells.

Keywords: corisin; apoptosis; organ fibrosis; parenchymal cells; different tissue

\section{Introduction}

Apoptosis is a programmed cell death with active participation in embryogenic development and maintenance of tissue homeostasis under physiological conditions [1]. It 
may be extrinsic or intrinsic, depending on the activation pathway. Extrinsic apoptosis is triggered by extracellular stress signals detected by transmembrane death receptors [1]. Intrinsic apoptosis is initiated by the mitochondrion, activated by the withdrawal of growth factors, hypoxia, oxidative stress, and finely regulated by the B-cell lymphoma 2 (Bcl-2) family of proteins $[2,3]$. Abnormalities in the process of apoptosis are implicated in the mechanism of several diseases. Defective apoptosis occurs in malignant tumors [4], autoimmune disorders [5], and infection by intracellular pathogens [6], whereas excessive apoptosis of organ parenchymal cells contributes to the pathogenesis of neurodegenerative diseases (e.g., Alzheimer's disease [7], amyotrophic lateral sclerosis [8], Parkinson's disease [9]), organ fibrosis (chronic kidney disease [10], liver cirrhosis [3], idiopathic pulmonary fibrosis [11], diabetic retinopathy [12], atopic dermatitis [13]), or vascular diseases (ischemic heart disease [14], cerebral ischemia [15], atherosclerosis [16]). The causative factors of apoptosis dysregulation are unclear. However, recent studies implicated the host microbiome in pathologic apoptosis [17-19].

The microbiome represents the complete genetic material harbored by microorganisms or microbiota that inhabit niches (e.g., skin, gut, lungs, urinary tract, eyes) of the human body [1]. The physiological function of the human microbiota is essential for nutrient degradation, biosynthesis of vitamins and amino acids, priming, and development of the immune system [1]. However, dysbiosis of the microbiome has been linked to disease development [20]. The mechanisms are not entirely clear; however, apoptosis of host cells has been reported to play a role. For example, oral dysbiosis is associated with enhanced apoptosis and disease progression in patients with chronic periodontitis and increased circulating levels of trimethylamine-n-oxide, a gut microbiota-dependent metabolite, promotes apoptosis of vascular smooth muscle cells and atherosclerosis in patients with chronic kidney disease [17-19]. In addition, we recently identified a peptide called corisin, released by Staphylococcus nepalensis strain CNDG from a fibrotic lung tissue, and this peptide induces apoptosis of alveolar epithelial cells and acute exacerbation of pulmonary fibrosis [21]. A significantly high level of the proapoptotic peptide was also detected in patients with idiopathic pulmonary fibrosis with acute exacerbation compared to patients without acute exacerbation and healthy controls, suggesting the pathogenic implication of corisin in the human lung fibrotic disease [21]. The evolutionary evaluation showed that the corisin sequence is highly conserved in the Staphylococcus genus, highlighting its functional significance [21].

In the present study, we hypothesized that corisin also induces apoptosis of cells from different tissues. To test our hypothesis, we cultured cell lines from different tissues with corisin and also a corisin-like peptide from S. haemolyticus and assessed the capacity to induce apoptosis in each cell line. Here, we report our findings that show that the corisin and corisin-like peptides trigger apoptosis in cell lines derived from multiple human tissues.

\section{Materials and Methods}

\subsection{Reagents}

The clear cell renal carcinoma (Caki-2) cell line derived from the epithelium of the proximal tubules, the in vitro spontaneously transformed aneuploidy immortal keratinocyte (HaCaT) cell line from adult human skin, the spontaneously arising retinal pigment epithelial (ARPE-19) cell line, the colon carcinoma (Caco-2) cell line and the normal human small intestinal epithelial cell-6 (HIEC-6) were obtained from the American Type Culture Collection (Manassas, VA, USA. RPMI 1640 medium was purchased from Sigma-Aldrich (St. Louis, MO, USA) and fetal bovine serum (FBS) from Bio Whittaker (Walkersville, MD, USA). L-glutamine, penicillin, and streptomycin were from Invitrogen (Carlsbad, CA, USA). The scrambled peptide (NRVYNGPAASPVSEQMPIN), the corisin (IVMPESSGNPNAVNPAGYR), and the corisin-like peptide (IVMPESGGNPNAVNPAGYR) were synthesized and provided by Peptide Institute Incorporation (Osaka, Japan). Transforming growth factor (TGF) $\beta 1$ was purchased from the R\&D System (Minneapolis, MN, USA). 


\subsection{Cell Culture}

Caki-2 cells, Caco- 2 cells, and immortalized human podocyte (ihPOD) were cultured in RPMI 1640 medium, HaCaT cells in high-glucose Dulbecco's Modified Eagle Medium (DMEM), ARPE-19 cells in DMEM/F12 medium, HIEC-6 cells in DMEM medium. Each medium was supplemented with 10\% fetal calf serum (FCS), $0.03 \%(\mathrm{w} / \mathrm{v})$ L-glutamine, $100 \mathrm{IU} / \mathrm{mL}$ penicillin, and $100 \mu \mathrm{g} / \mathrm{mL}$ streptomycin. The cells were cultured in a humidified, $5 \% \mathrm{CO}_{2}$ atmosphere at $37^{\circ} \mathrm{C}$. The experiments were undertaken 10 days after seeding, when cells became differentiated.

\subsection{Evaluation of Cell Apoptosis}

The cells were cultured up to subconfluency. The cells were then washed and cultured overnight in an FCS-free medium. The cells were stimulated with $10 \mu \mathrm{g} / \mathrm{mL}$ of scrambled peptide, corisin, or corisin-like peptide and cultured for $48 \mathrm{~h}$ before collecting the cells for apoptosis evaluation by flow cytometry. To evaluate cleavage of caspase- 3 by Western blotting, the cells were cultured and stimulated similarly with each peptide for $24 \mathrm{~h}$ before cell harvesting. To evaluate the synergism of corisin with TGF $\beta 1$, podocytes were cultured in the presence of both TGF $\beta 1$ and corisin for $48 \mathrm{~h}$ before evaluating apoptosis. As a control, we performed the same experiment, but with corisin replaced with its scrambled peptide.

\subsection{Flow Cytometry Analysis}

The cells were analyzed for apoptosis by flow cytometry (FACScan, BD Biosciences, Oxford, UK) after staining with fluorescein-labeled annexin $\mathrm{V}$ and propidium iodide (FITC Annexin V Apoptosis Detection Kit with PI, Biolegend, San Diego, CA, USA).

\subsection{Western Blotting}

The cells were washed with ice-cold phosphate-buffered saline and treated with radioimmunoprecipitation assay (RIPA) lysis buffer supplemented with protease/phosphatase inhibitors. After cell centrifugation, the protein concentration was determined using the Pierce BCA protein assay kit (Thermo Fisher Scientific Incorporation, Waltham, MA, USA). Cellular lysate protein was mixed with Laemmli sample buffer, applied to a sodium dodecyl sulfate-polyacrylamide gel, and electrophoresis was run. After electrophoretically transferring the proteins from the gel to nylon membranes, Western blotting was performed using anti-cleaved caspase- 3 or anti- $\beta$-actin antibody (Cell Signaling, Danvers, MA, USA) as previously described [20]. The intensity of the bands was quantified by densitometry using the public domain NIH ImageJ program (wayne@codon.nih.gov; Wayne Rasband, $\mathrm{NIH}$, Research Service Branch).

\subsection{Evaluation of Reactive Oxygen Species during Corisin-Induced Apoptosis}

Caco-2 cells were pre-incubated with or without $\mathrm{N}$-acetyl-1-cysteine, a reactive oxygen species (ROS) inhibitor, for $1 \mathrm{~h}$, treated with $10 \mu \mathrm{g} / \mathrm{mL}$ of corisin or scrambled peptide for $48 \mathrm{~h}$ then apoptosis was evaluated by flow cytometry. To detect cellular ROS, Caco- 2 cells $\left(2 \times 10^{5}\right.$ cells $/$ well $)$ cultured in a 12-well plate were treated with $5 \mu \mathrm{M}$ corisin or scrambled peptide for $48 \mathrm{hrs}$. Cells were washed with phosphate-buffered saline (PBS) and incubated with RPMI-1640 medium containing $20 \mu \mathrm{M} 2^{\prime}, 7^{\prime}$-dichlorofluorescin diacetate (DCFDA) (R\&D Systems, Minneapolis, MN, USA) for $20 \mathrm{~min}$ in the dark at $37^{\circ} \mathrm{C}$. Fluorescence intensity of DCF was detected using a BD FACScan flow cytometer. Data were analyzed using the BD CellQuest software.

\subsection{Mitochondrial Membrane Potential Assay}

Loss of mitochondrial membrane integrity was measured using the fluorescent dye JC-1 (5,5' , 6, $6^{\prime}$-tetrachloro-1,1' , 3,3'-tetraethyl tetrethyl benzimidalyl carbocyanine iodide) from Dojindo (Kumamoto, Japan). Changes in mitochondrial membrane potential were expressed as a ratio of red $(585 \mathrm{~nm})$ to green $(530 \mathrm{~nm})$ fluorescence. In the assay, Caco-2 cells were treated with $10 \mu \mathrm{g} / \mathrm{mL}$ of corisin or scrambled peptide for $48 \mathrm{~h}$, and then cells 
were stained with $2 \mu \mathrm{M} \mathrm{JC}-1$ for $20 \mathrm{~min}$ at $37^{\circ} \mathrm{C}$. JC- 1 fluorescence was detected using BD FACScan flow cytometry, and data were analyzed using BD CellQuant software.

\subsection{Statistical Analysis}

Data were expressed as the mean \pm standard deviation of the means (S.D.). The statistical difference between variables was calculated by analysis of variance (ANOVA) with Newman-Keuls' test. Statistical analyses were performed using the GraphPad Prism version 7.0 (GraphPad Software, San Diego, CA, USA). A $p<0.05$ was considered statistically significant.

\section{Results}

\subsection{Differential Proapoptotic Activity of Corisin and Corisin-like Peptide on Cells from} Different Tissues

Corisin and corisin-like peptides significantly induced apoptosis of cultured colon epithelial (Caco-2) cells and small intestinal (HIEC-6) epithelial cells compared to the scrambled peptide. The proapoptotic activity of the corisin-like peptide, which differs in one amino acid from corisin $(7 \mathrm{~S} \rightarrow 7 \mathrm{G}$ ), is slightly weaker than corisin (Figure 1A,B). Corisin and corisin-like peptides also significantly induced apoptosis of keratinocytes (HaCaT) and retinal (ARPE-19) cells compared to the scrambled peptide (Figure 2A,B). Although at less degree than Caco-2 and $\mathrm{HaCaT}$ cells, podocytes (ihPOD) and renal tubular (Caki-2) cells also underwent apoptosis in the presence of corisin or corisin-like peptide (Figure 3A,B). Evaluation of caspase-3 activity showed a significantly increased cleavage of caspase-3 in all cells treated with corisin and corisin-like peptides compared to cells treated with scrambled peptides, indicating activation of the apoptotic pathway (Figure 4A,B).

\subsection{Corisin Potentiates the Proapoptotic Activity of TGF $\beta 1$ on Podocytes}

The podocytes were cultured up to subconfluency, serum-starved, and then treated with a combination of TGF $\beta 1(5 \mathrm{ng} / \mathrm{mL})$ and corisin $(5 \mu \mathrm{g} / \mathrm{mL})$ for $48 \mathrm{~h}$ before cell harvesting to assess apoptosis. Corisin alone induced weak apoptosis of podocytes, but it significantly potentiated the apoptotic activity of TGF $\beta 1$ on podocytes (Figure $5 \mathrm{~A}, \mathrm{~B}$ ).

\subsection{Increased Generation of Reactive Oxygen Species and Loss of Mitochondrial Membrane} Integrity during Apoptosis Induced by Corisin

$\mathrm{N}$-Acetyl-1-cysteine, an inhibitor of reactive oxygen species, significantly suppressed apoptosis induced by corisin in Caco-2 cells compared to controls (Figure 6A,B). We also measured the generation of ROS using the ROS-sensitive DCFDA dye. There was a significantly increased ROS accumulation in cells treated with corisin compared to scrambled peptide-treated cells (Figure 6C,D). In addition, evaluation of the mitochondrial membrane potential using the JC-1 dye disclosed a significant reduction in the red to green fluorescence intensity ratio indicating mitochondrial membrane depolarization in Caco-2 cells treated with corisin compared to cells treated with scrambled peptide (Figure 6E,F). 
A

Caco-2
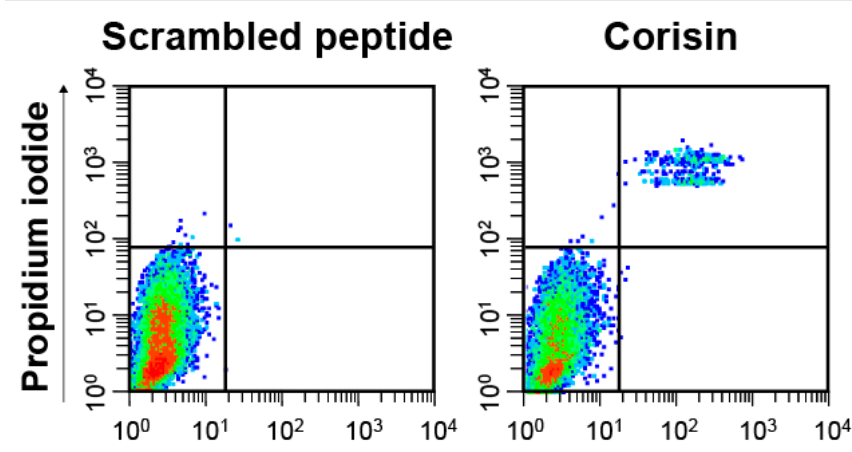

Corisin-like peptide
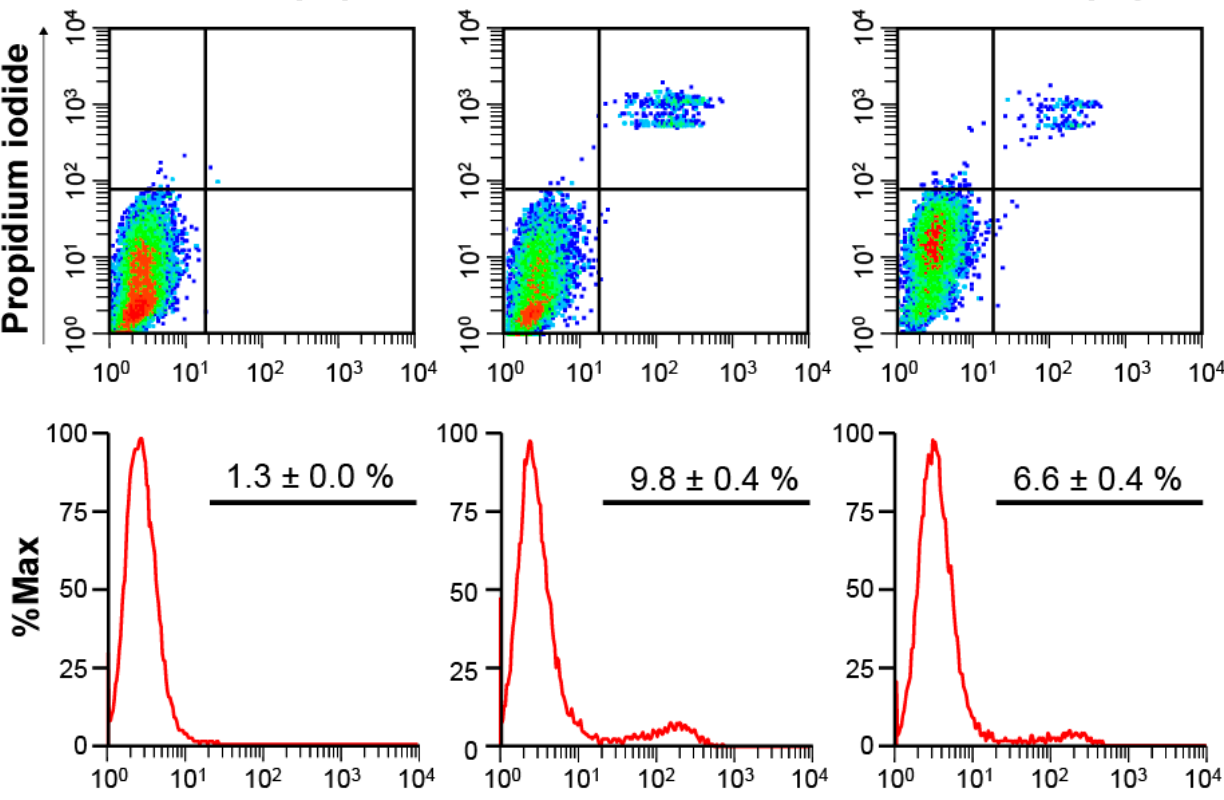

\section{Annexin V}
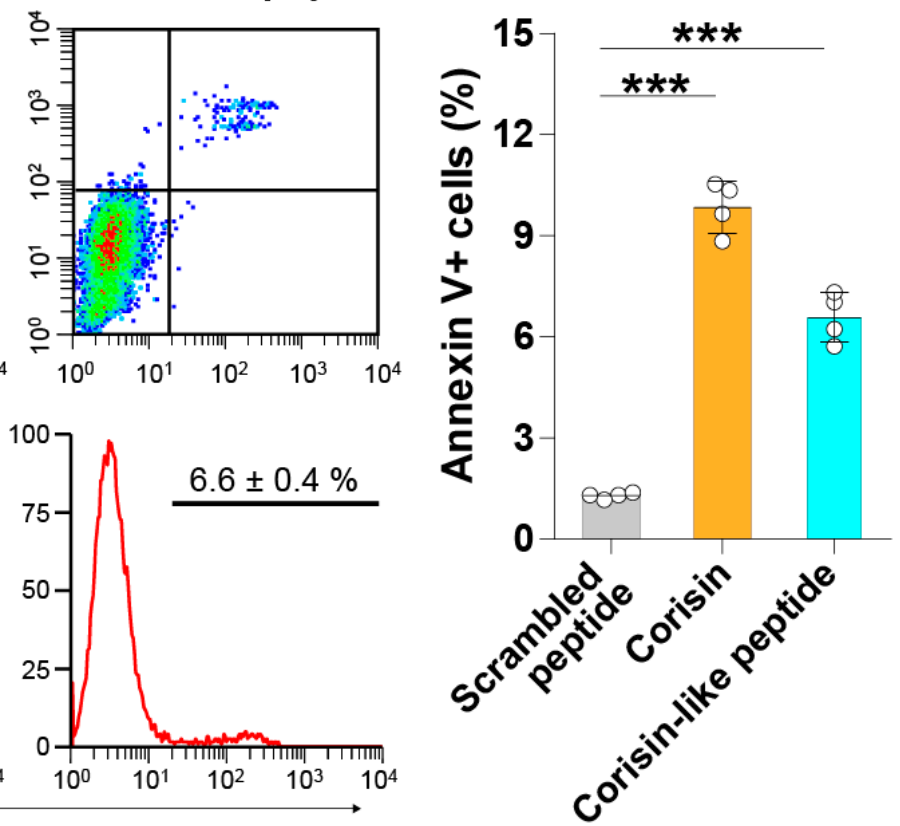

B

HIEC-6
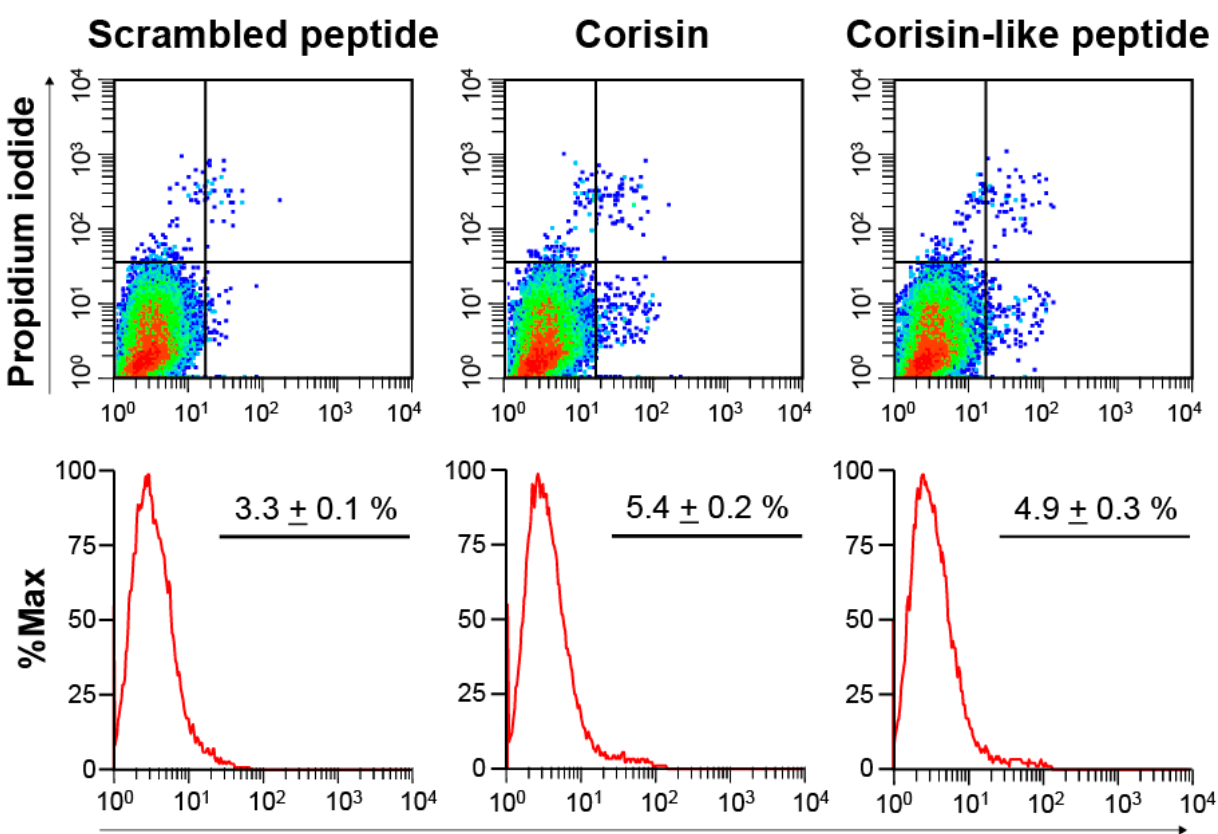

Annexin V

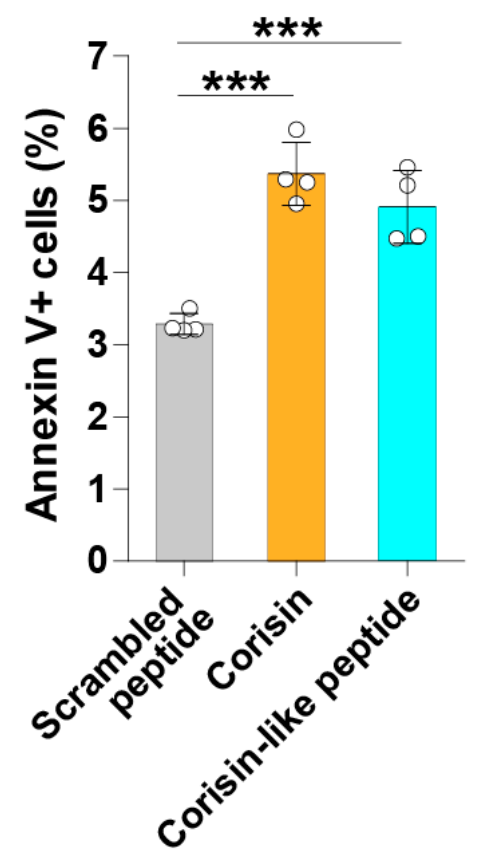

Figure 1. Corisin and corisin-like peptide induce apoptosis of intestinal cells. Caco-2 (A) and HIEC-6 (B) cells were cultured in the presence of corisin or corisin-like peptides for $48 \mathrm{~h}$, and apoptosis was evaluated by flow cytometry. Data are expressed as the mean \pm S.D. Statistical analysis by ANOVA with Newman-Keuls' test. ${ }^{* * *} p<0.001$. 
A

HaCaT

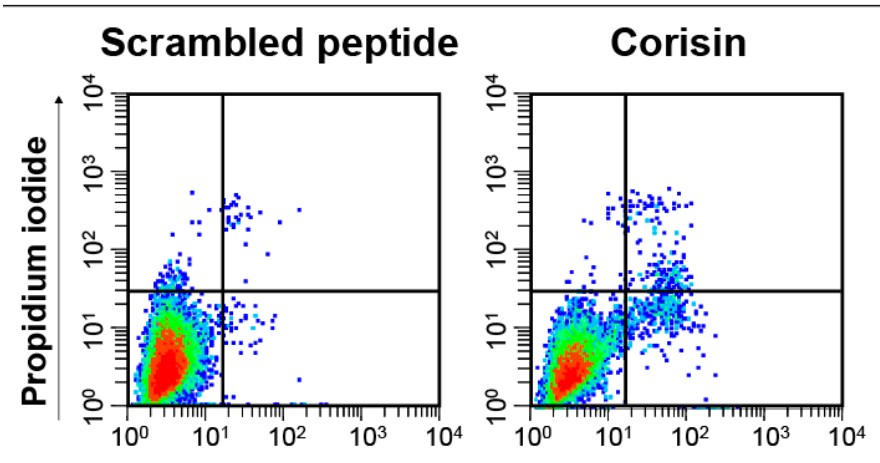

Corisin-like peptide
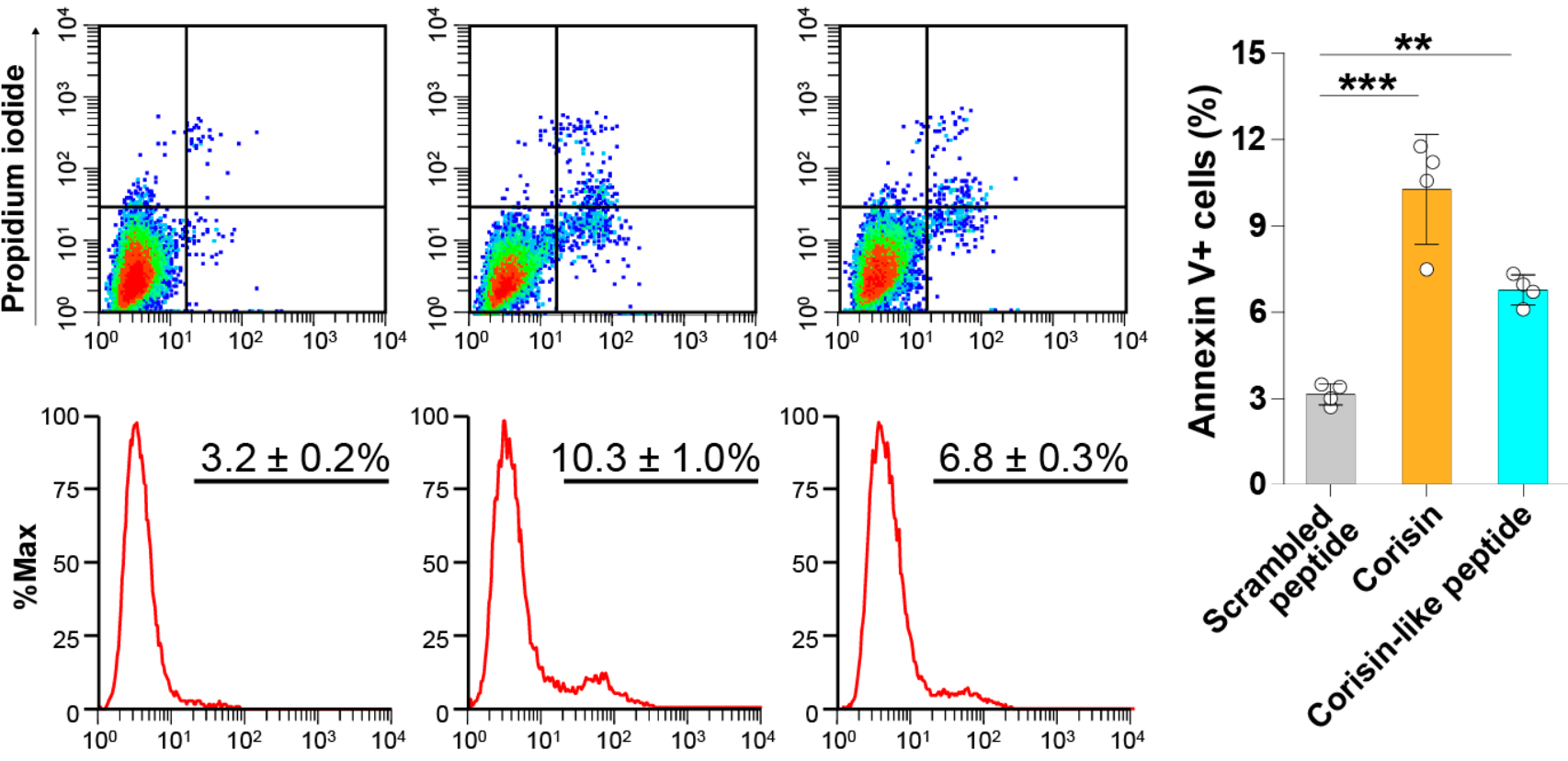

B

ARPE-19
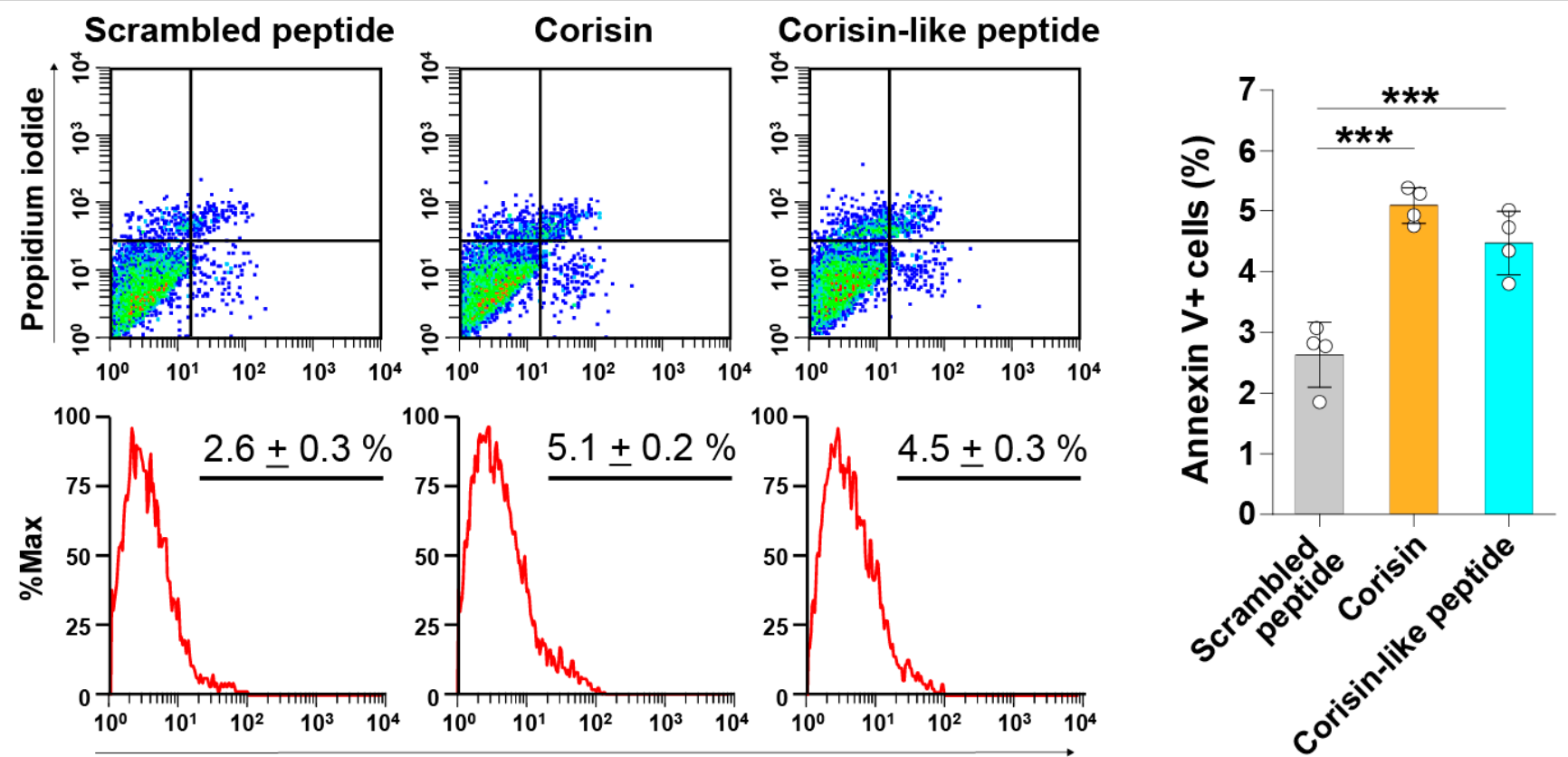

Figure 2. Corisin and corisin-like peptides induce apoptosis of keratinocytes and retinal cells. HaCaT (A) cells and ARPE-19 cells (B) were cultured in the presence of corisin or corisin-like peptide for $48 \mathrm{~h}$, and apoptosis was evaluated by flow cytometry. Data are expressed as the mean \pm S.D. Statistical analysis by ANOVA with Newman-Keuls' test. ${ }^{* *} p<0.01$; $* * * p<0.001$. 
A

ihPOD
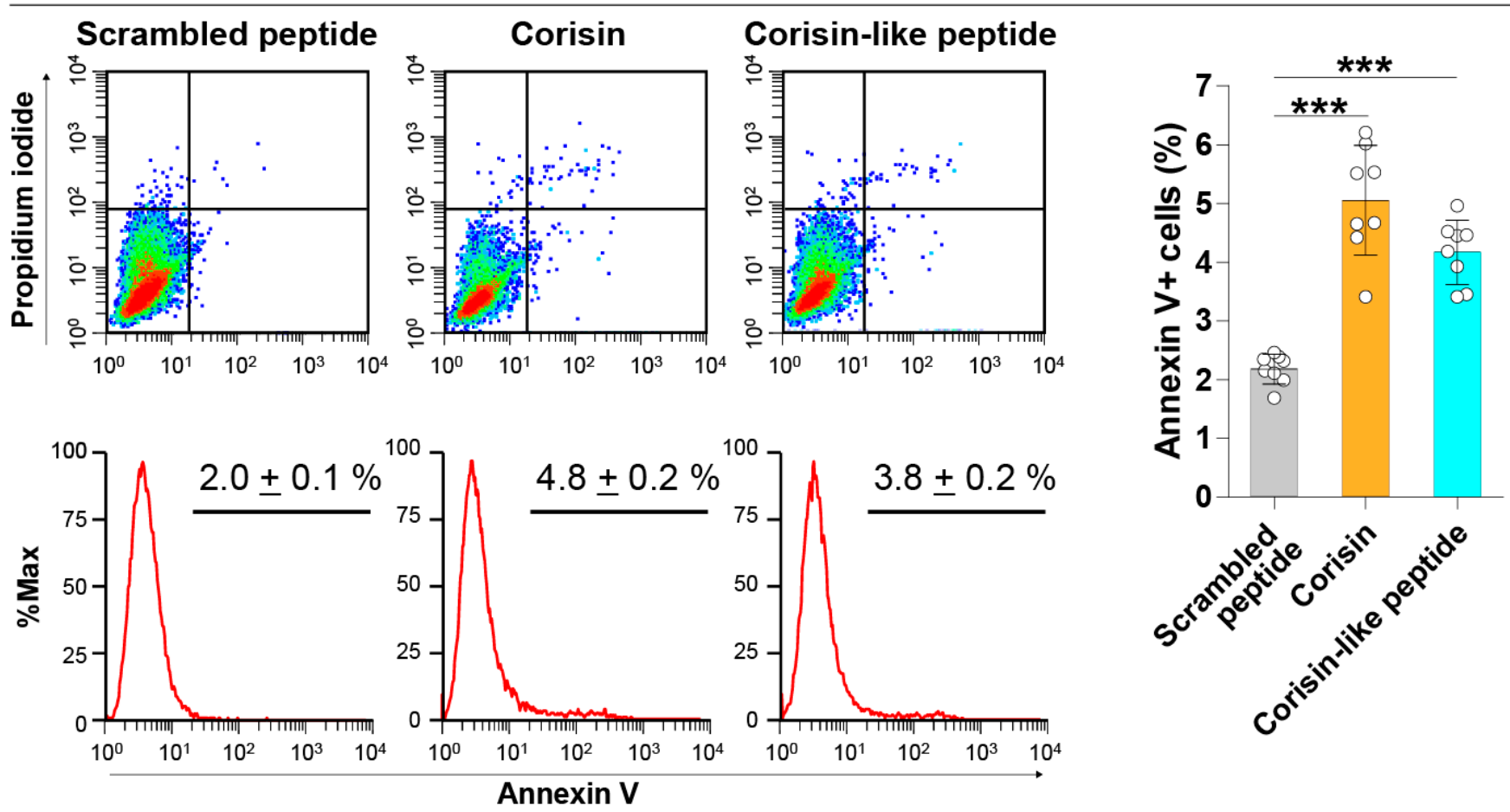

B

Caki-2
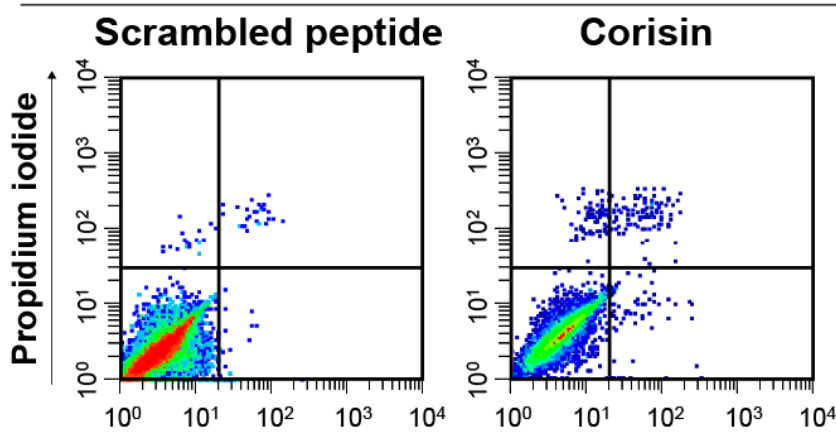

Corisin-like peptide
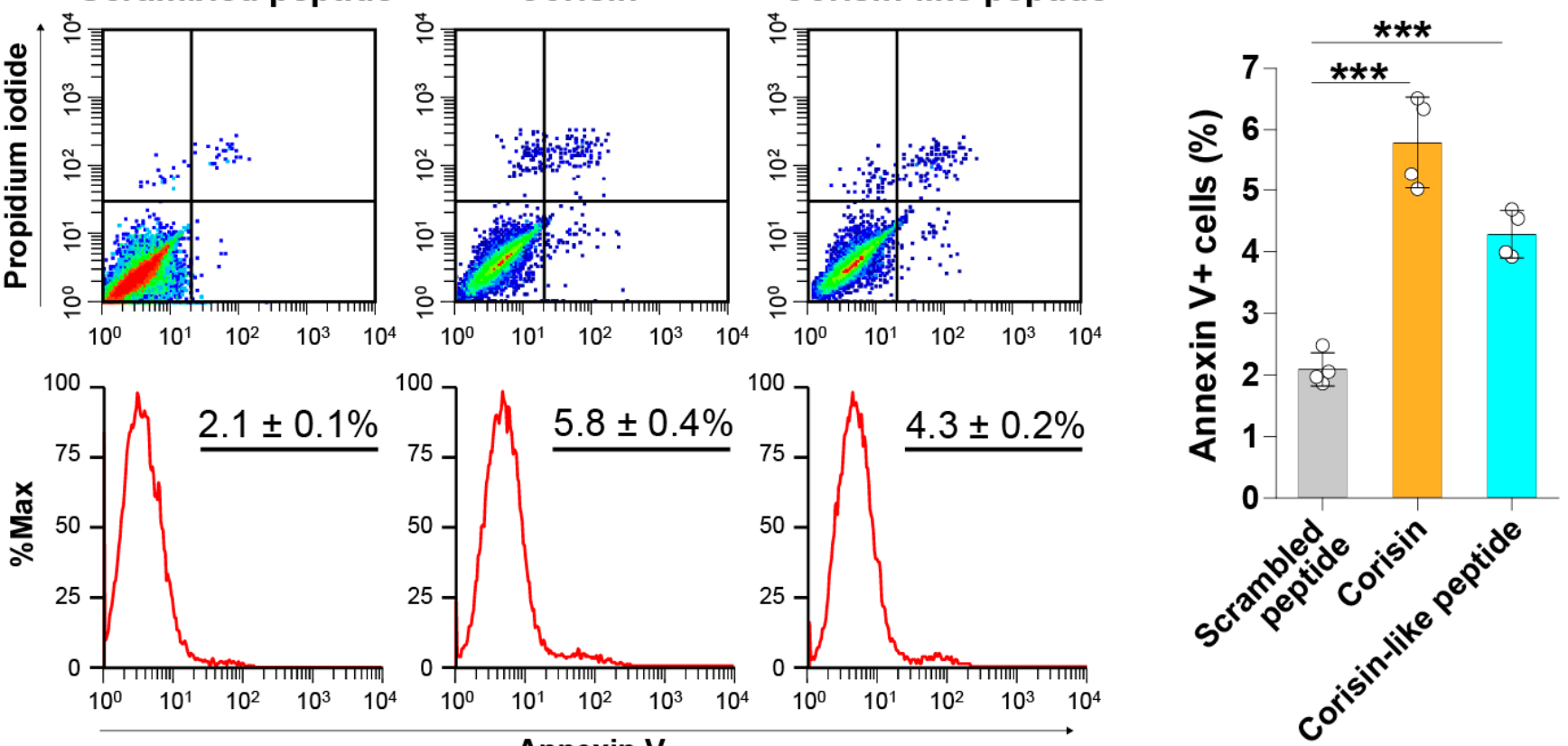

Figure 3. Corisin and corisin-like peptide induce apoptosis of podocytes and renal tubular epithelial cells. Podocytes (A) and Caki-2 cells (B) were cultured in the presence of corisin or corisin-like peptide for $48 \mathrm{~h}$, and apoptosis was evaluated by flow cytometry. Data are expressed as the mean \pm S.D. Statistical analysis by ANOVA with Newman-Keuls' test. $* * * p<0.001$. 
A
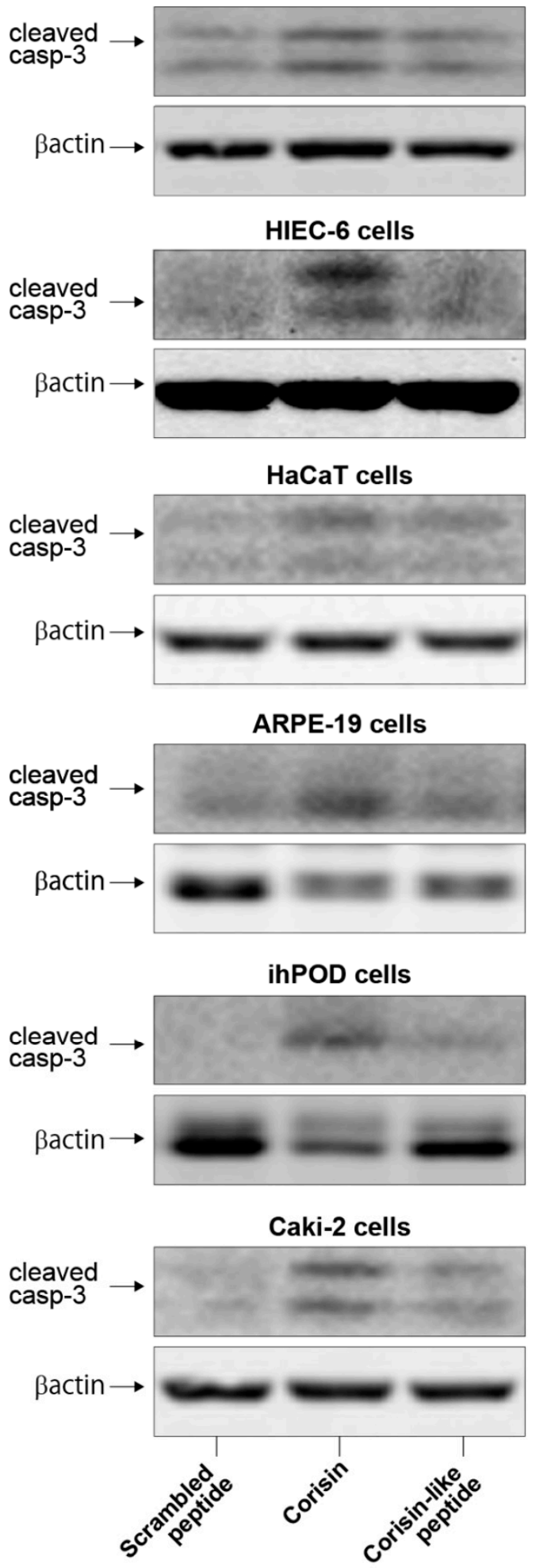

B Caco-2 cells

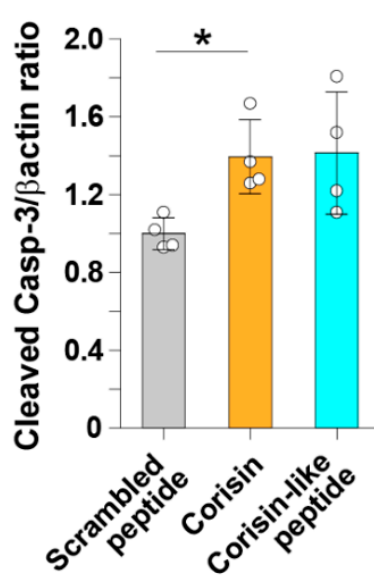

HaCaT cells

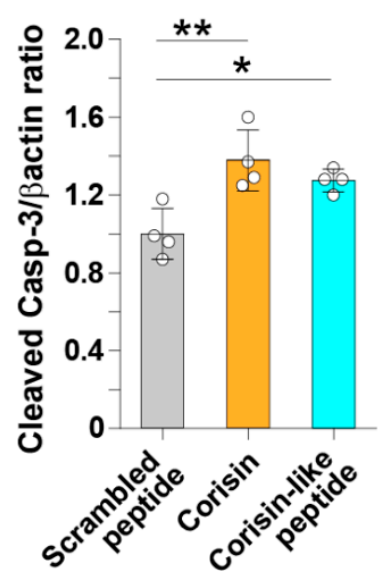

inPOD cells

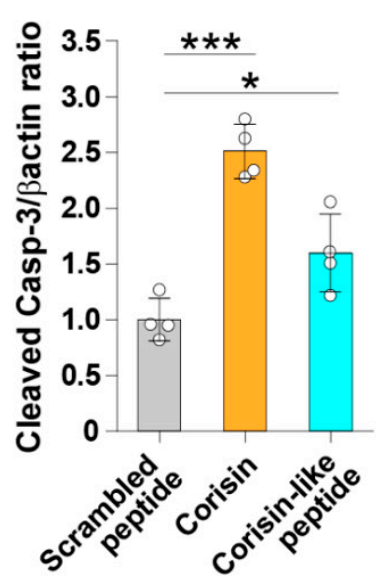

HIEC-6 cells
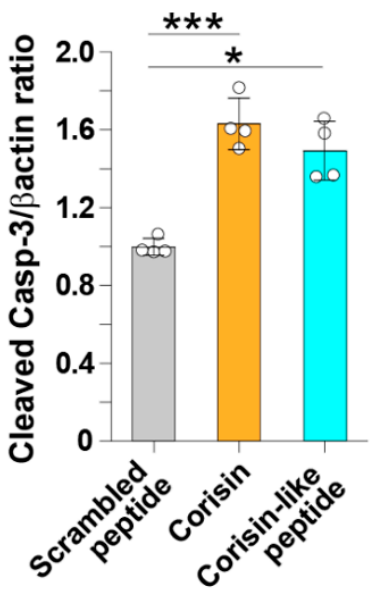

ARPE-19 cells

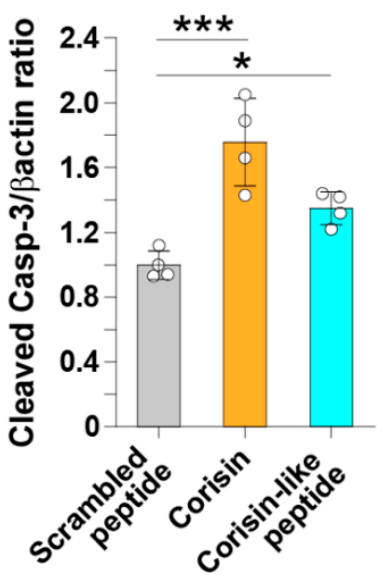

Caki-2 cells

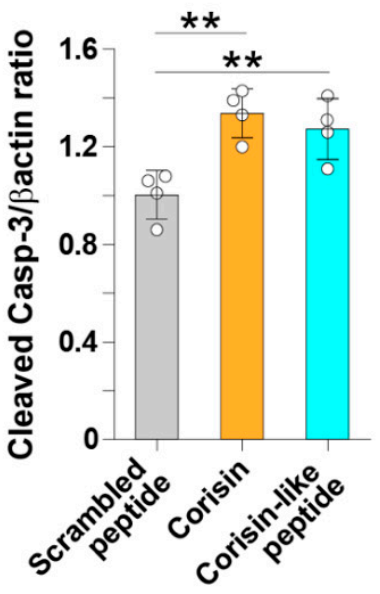

Figure 4. Cleavage of caspase-3 in cells treated with corisin or corisin-like peptide. Colon (Caco-2) epithelial cells, small intestinal (HIEC-6) cells, keratinocytes (HaCaT cells), retinal (ARPE-19) cells, podocytes (ihPOD), and renal tubular epithelial (Caki-2) cells were cultured in the presence of corisin or corisin-like peptide for $24 \mathrm{~h}$, and apoptosis was evaluated by Western blotting (A). Densitometry analysis was performed using ImageJ (B). Data are expressed as the mean \pm S.D. Statistical analysis by ANOVA with Newman-Keuls' test. ${ }^{*} p<0.05,{ }^{* *} p<0.01,{ }^{* * *} p<0.001$. 
A

inPOD

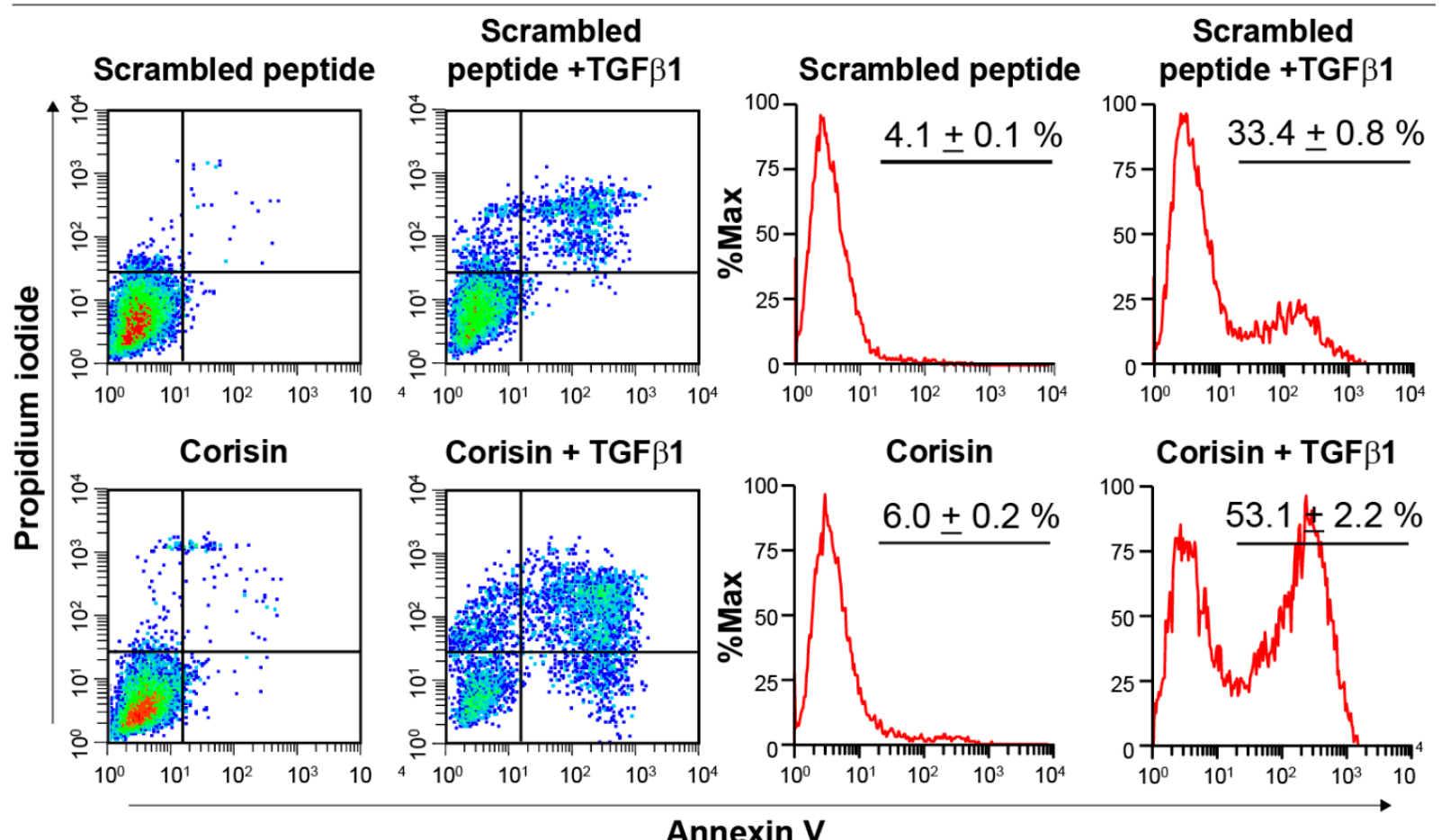

B

Annexin V

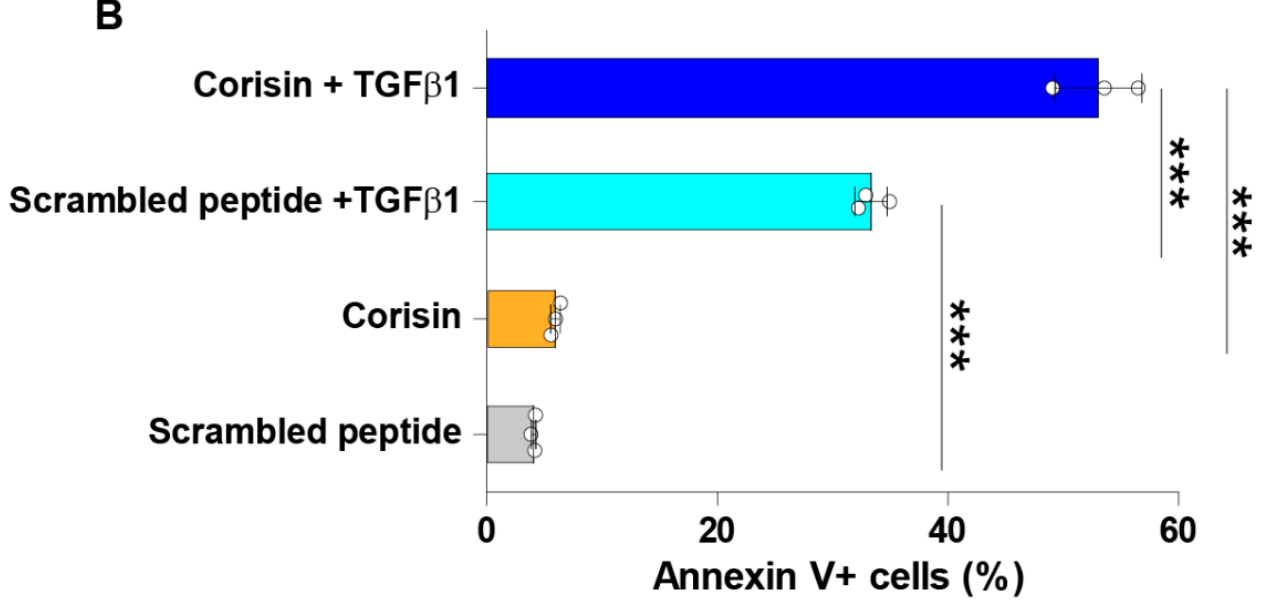

Figure 5. Corisin potentiates the proapoptotic activity of transforming growth factor- $\beta 1$ synergistically. Podocytes were cultured in the presence of scrambled peptide alone, corisin alone, or TGF $\beta 1$ in combination with scrambled peptide or corisin for $48 \mathrm{~h}$ and the degree of apoptosis was evaluated by flow cytometry (A). The number of cells was expressed in percentage (B). Data are expressed as the mean \pm S.D. Statistical analysis by ANOVA with Newman-Keuls' test. ${ }^{* * *} p<0.001$. 

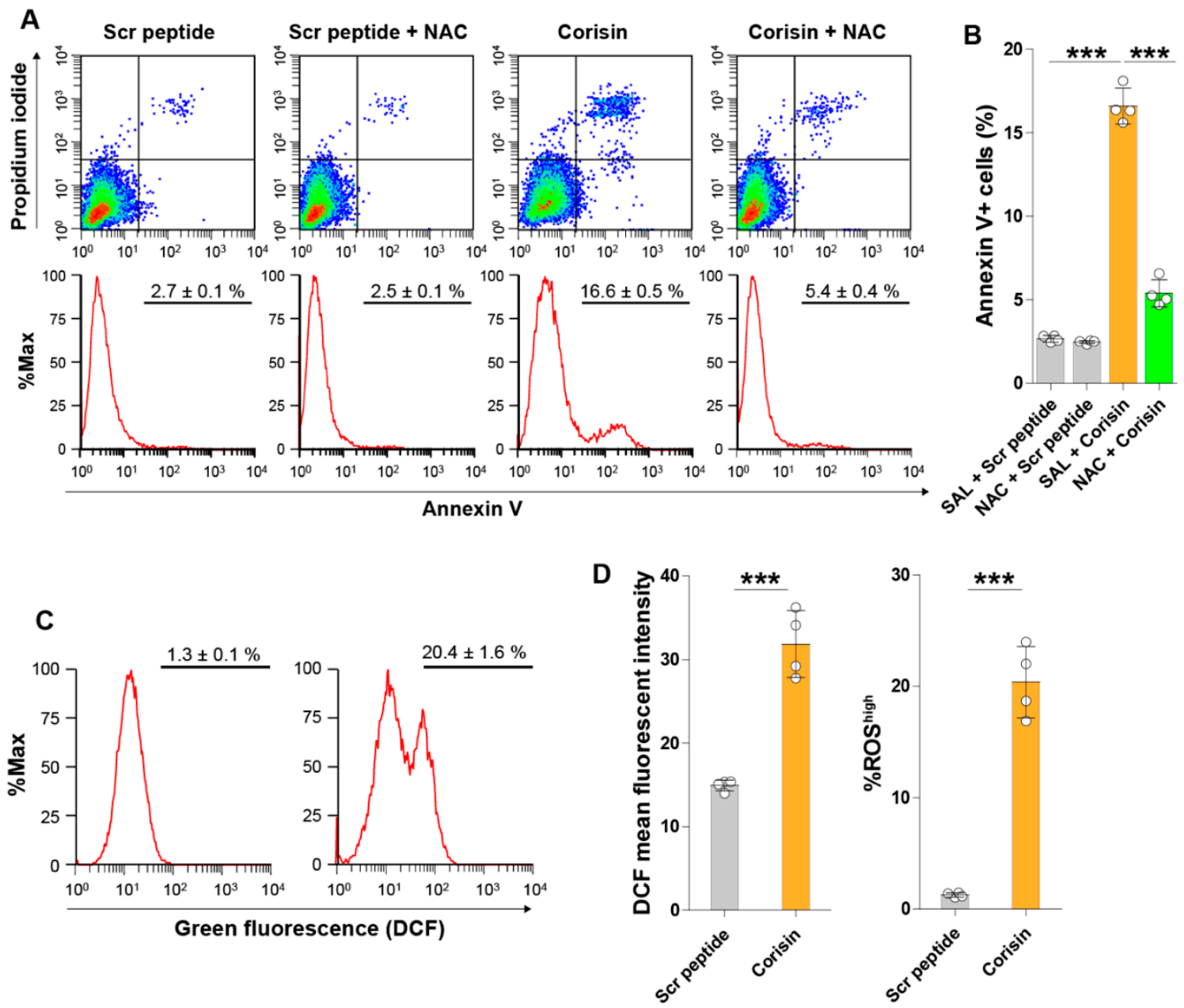

E
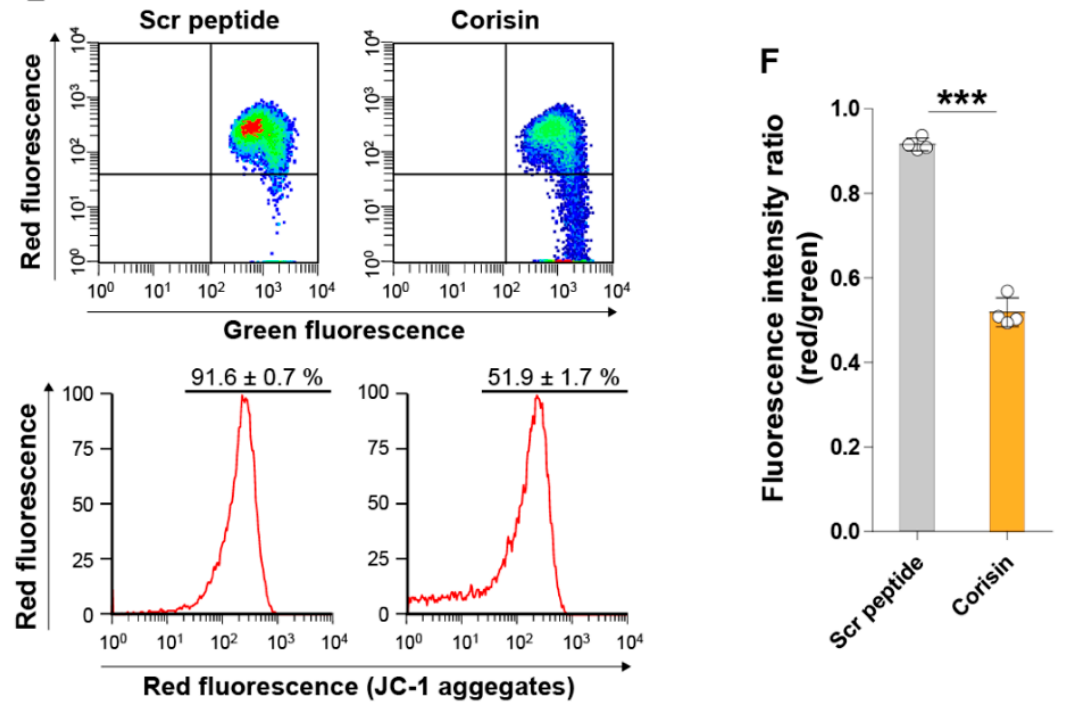

Figure 6. Treatment of intestinal cells is associated with increased generation of reactive oxygen species (ROS) and mitochondrial membrane depolarization. Caco-2 cells were pre-incubated with or without $\mathrm{N}$-acetyl-1-cysteine and then treated with $10 \mu \mathrm{g} / \mathrm{mL}$ of corisin or scrambled peptide before evaluating apoptosis by flow cytometry $(\mathbf{A}, \mathbf{B})$. To detect cellular ROS, Caco-2 cells were treated with $5 \mu \mathrm{M}$ corisin or scrambled peptide, washed with phosphate-buffered saline, incubated with medium containing $2^{\prime}, 7^{\prime}$-dichlorofluorescin diacetate (DCFDA) and then evaluated by flow cytometry (C,D). The JC-1 dye was used to evaluate mitochondrial membrane integrity. Caco-2 cells were treated with corisin or scrambled peptide, and then cells were stained with JC-1 before assessing by flow cytometry (E,F). Data are expressed as the mean \pm S.D. Statistical analysis by ANOVA with Newman-Keuls' test. ${ }^{* * *} p<0.001$. 


\section{Discussion}

This study shows that microbiome-derived peptides induce apoptosis of cells from different tissues and that corisin enhances the proapoptotic activity of TGF $\beta 1$ on podocytes synergistically.

Corisin was originally identified in the culture supernatant of S. nepalensis isolated from the fibrotic lung tissue of transgenic mice with lung-specific overexpression of the human TGF $\beta 1$ gene [21]. Corisin is a fragment of bacterial transglycosylase, and its sequence is well conserved among microbes of the genus Staphylococcus [21]. Staphylococci are important members of the human microbiota [22]. Therefore, it is reasonable to speculate that in addition to the lungs, corisin production also occurs in other microbiota niches of the body and that it is involved in the pathological states of other organs. A mounting body of evidence showed that increased death of parenchymal cells plays a critical role in the pathogenesis of chronic kidney disease [10], chronic dermatitis [13], intestinal bowel disease [23], and diabetic retinopathy [12]. However, the causative factor of excessive cell death and whether the microbiome plays a role in the mechanism remain unclear. In the present study, we found that corisin induces apoptosis of keratinocytes, podocytes, renal tubular epithelial cells, intestinal and retinal cells, suggesting the potential pathogenic implication of corisin in the mechanism of cell death observed in intractable diseases. In line with this observation, the culture of intestinal cells in the presence of corisin was associated with increased ROS generation and loss of mitochondrial membrane integrity.

We previously reported that low levels of corisin can be detected by enzyme immunoassay in the bronchoalveolar lavage fluid of healthy subjects and the lung tissue by Western blotting, showing the existence of a baseline level of corisin released from the microbiome under physiological conditions [21]. Being a recently discovered proapoptotic factor, the physiological function of corisin or corisin-like peptides is currently unknown. However, we hypothesized that under pathological conditions in the presence of enhanced local levels of other proapoptotic factors such as TGF $\beta 1$ or tumor necrosis factor- $\alpha$, even low concentrations of corisin may be sufficient to trigger cell death [24]. To test this hypothesis, we cultured podocytes and compared the degree of apoptosis induced in the presence of scrambled peptide, corisin alone, and in the presence of both TGF $\beta 1$ and corisin or scrambled peptide. The addition of corisin synergistically increased the degree of podocytes apoptosis induced by TGF $\beta 1$ alone plus scrambled peptide. Existing data indicate that TGF $\beta 1$ induces proliferation of fibroblasts, deposition of extracellular matrix, and podocytes apoptosis in chronic glomerulosclerosis. Therefore, the current study results suggest that corisin may further potentiate the detrimental effect of TGF $\beta 1$ in kidney fibrosis.

In brief, this study shows that microbiome-derived peptides induce apoptosis of cells from different tissues and that corisin enhances the proapoptotic activity of TGF $\beta 1$ on podocytes synergistically. Our observation that corisin is stable in the body fluid further suggests that irrespective of where it is produced, (e.g., lung, intestinal, urinal tract) corisin has the potential to induce some form of systemic apoptosis, although in many tissues it may be low grade in nature.

\section{Patents}

C.N.D.-G., E.C.G. and I.C. have issued a patent on the apoptotic peptides described in this study and anticorisin monoclonal antibodies.

Author Contributions: Conceptualization, E.C.G., I.C. and T.K.; methodology, T.Y., M.T., C.N.D.-G., A.M.A.-H., H.F., A.T. and T.T.; data validation, T.Y., A.T., H.F.; formal analysis, M.T., V.F.D., Y.O., H.S. and T.T.; resources, K.K., M.S., K.Y., I.C. and A.M.A.-H.; original draft preparation, H.S., Y.O., C.N.D.-G. and T.K.; review and editing, E.C.G., K.K., M.S., K.Y. and H.F.; supervision, E.C.G., C.N.D.-G. and T.K.; project administration, C.N.D.-G.; funding acquisition, E.C.G., T.Y. and A.T. All authors have read and agreed to publish the manuscript. 
Funding: This study was funded in part by Grants $(20 K 08564 ; 21 K 1685 ; 19 K 17960 ; 21 K 16116$; 19K17738 and 21K16160) from the Japan Society for the Promotion of Science, in part by a Grant from Takeda Science Foundation (2019) and in part by funding support to the Microbiome Metabolic Engineering (MME) Theme, Carl R. Woese Institute for Genomic Biology.

Institutional Review Board Statement: Not applicable.

Informed Consent Statement: Not applicable.

Data Availability Statement: All data obtained during the current study are available from the corresponding author upon reasonable request.

Conflicts of Interest: E.C.G., C.N.D.-G., and I.C. have issued a patent on corisin and anticorisin monoclonal antibodies. Other authors declared no conflict of interest regarding data reported in this work.

\section{References}

1. Singh, R.; Letai, A.; Sarosiek, K. Regulation of apoptosis in health and disease: The balancing act of BCL-2 family proteins. Nat. Rev. Mol. Cell Biol. 2019, 20, 175-193. [CrossRef]

2. Gillies, L.A.; Kuwana, T. Apoptosis regulation at the mitochondrial outer membrane. J. Cell Biochem. 2014, 115, 632-640. [CrossRef]

3. Li, X.; Wang, Y.; Wang, H.; Huang, C.; Huang, Y.; Li, J. Endoplasmic reticulum stress is the crossroads of autophagy, inflammation, and apoptosis signaling pathways and participates in liver fibrosis. Inflamm. Res. 2015, 64, 1-7. [CrossRef]

4. Evan, G.I.; Vousden, K.H. Proliferation, cell cycle and apoptosis in cancer. Nature 2001, 411, 342-348. [CrossRef]

5. Strasser, A.; Whittingham, S.; Vaux, D.L.; Bath, M.L.; Adams, J.M.; Cory, S.; Harris, A.W. Enforced BCL2 expression in B-lymphoid cells prolongs antibody responses and elicits autoimmune disease. Proc. Natl. Acad. Sci. USA 1991, 88, 8661-8665. [CrossRef]

6. Sly, L.M.; Hingley-Wilson, S.M.; Reiner, N.E.; McMaster, W.R. Survival of Mycobacterium tuberculosis in host macrophages involves resistance to apoptosis dependent upon induction of antiapoptotic Bcl-2 family member Mcl-1. J. Immunol. 2003, 170, 430-437. [CrossRef]

7. Rohn, T.T. The role of caspases in Alzheimer's disease; potential novel therapeutic opportunities. Apoptosis 2010, 15, 1403-1409. [CrossRef] [PubMed]

8. Reyes, N.A.; Fisher, J.K.; Austgen, K.; VandenBerg, S.; Huang, E.J.; Oakes, S.A. Blocking the mitochondrial apoptotic pathway preserves motor neuron viability and function in a mouse model of amyotrophic lateral sclerosis. J. Clin. Investig. 2010, 120, 3673-3679. [CrossRef] [PubMed]

9. Blesa, J.; Przedborski, S. Parkinson's disease: Animal models and dopaminergic cell vulnerability. Front. Neuroanat. 2014, 8, 155. [CrossRef] [PubMed]

10. Tesch, G.H.; Ma, F.Y.; Nikolic-Paterson, D.J. Targeting apoptosis signal-regulating kinase 1 in acute and chronic kidney disease. Anat. Rec. 2020, 303, 2553-2560. [CrossRef]

11. Thannickal, V.J.; Horowitz, J.C. Evolving concepts of apoptosis in idiopathic pulmonary fibrosis. Proc. Am. Thorac. Soc. 2006, 3, 350-356. [CrossRef]

12. Adamiec-Mroczek, J.; Zajac-Pytrus, H.; Misiuk-Hojlo, M. Caspase-Dependent Apoptosis of Retinal Ganglion Cells during the Development of Diabetic Retinopathy. Adv. Clin. Exp. Med. 2015, 24, 531-535. [CrossRef] [PubMed]

13. Rebane, A.; Zimmermann, M.; Aab, A.; Baurecht, H.; Koreck, A.; Karelson, M.; Abram, K.; Metsalu, T.; Pihlap, M.; Meyer, N.; et al. Mechanisms of IFN-gamma-induced apoptosis of human skin keratinocytes in patients with atopic dermatitis. J. Allergy Clin. Immunol. 2012, 129, 1297-1306. [CrossRef]

14. Teringova, E.; Tousek, P. Apoptosis in ischemic heart disease. J. Transl. Med. 2017, 15, 87. [CrossRef]

15. Hayakawa, K.; Esposito, E.; Wang, X.; Terasaki, Y.; Liu, Y.; Xing, C.; Ji, X.; Lo, E.H. Transfer of mitochondria from astrocytes to neurons after stroke. Nature 2016, 535, 551-555. [CrossRef]

16. Linton, M.F.; Babaev, V.R.; Huang, J.; Linton, E.F.; Tao, H.; Yancey, P.G. Macrophage Apoptosis and Efferocytosis in the Pathogenesis of Atherosclerosis. Circ. J. 2016, 80, 2259-2268. [CrossRef]

17. Ebersole, J.L.; Kirakodu, S.S.; Gonzalez, O.A. Oral microbiome interactions with gingival gene expression patterns for apoptosis, autophagy and hypoxia pathways in progressing periodontitis. Immunology 2021, 162, 405-417. [CrossRef] [PubMed]

18. Ebersole, J.L.; Kirakodu, S.S.; Neumann, E.; Orraca, L.; Gonzalez Martinez, J.; Gonzalez, O.A. Oral Microbiome and Gingival Tissue Apoptosis and Autophagy Transcriptomics. Front. Immunol. 2020, 11, 585414. [CrossRef]

19. Zhang, X.; Li, Y.; Yang, P.; Liu, X.; Lu, L.; Chen, Y.; Zhong, X.; Li, Z.; Liu, H.; Ou, C.; et al. Trimethylamine-N-Oxide Promotes Vascular Calcification Through Activation of NLRP3 (Nucleotide-Binding Domain, Leucine-Rich-Containing Family, Pyrin Domain-Containing-3) Inflammasome and NF-kappaB (Nuclear Factor kappaB) Signals. Arterioscler. Thromb. Vasc. Biol. 2020, 40, 751-765. [CrossRef]

20. Ohtani, N.; Kawada, N. Role of the gut-liver axis in liver inflammation, fibrosis, and cancer: A special focus on the gut microbiota relationship. Hepatol. Commun. 2019, 3, 456-470. [CrossRef] [PubMed] 
21. D'Alessandro-Gabazza, C.N.; Kobayashi, T.; Yasuma, T.; Toda, M.; Kim, H.; Fujimoto, H.; Hataji, O.; Takeshita, A.; Nishihama, K.; Okano, T.; et al. A Staphylococcus pro-apoptotic peptide induces acute exacerbation of pulmonary fibrosis. Nat. Commun. 2020, 11, 1539. [CrossRef] [PubMed]

22. Otto, M. Staphylococci in the human microbiome: The role of host and interbacterial interactions. Curr. Opin. Microbiol. 2020, 53, 71-77. [CrossRef] [PubMed]

23. Cao, S.S. Cellular Stress Responses and Gut Microbiota in Inflammatory Bowel Disease. Gastroenterol. Res. Pract. 2018, 2018, 7192646. [CrossRef] [PubMed]

24. Tang, P.C.; Chan, A.S.; Zhang, C.B.; Garcia Cordoba, C.A.; Zhang, Y.Y.; To, K.F.; Leung, K.T.; Lan, H.Y.; Tang, P.M. TGF-beta1 Signaling: Immune Dynamics of Chronic Kidney Diseases. Front. Med. 2021, 8, 628519. 